\title{
Validation of Practices for Effective Communication during Requirements Elicitation in Global Software Development
}

\author{
Atta Ur Rahman \\ Department of Computer Science \\ COMSATS University Islamabad \\ Islamabad
}

\author{
Sadiq Khan \\ Department of Computer Science \\ International Islamic University \\ Islamabad
}

\author{
Noman Sarwar \\ Department of Computer and \\ Software Technology \\ University of Swat
}

\author{
Muhammad Yaseen \\ City University of Science and \\ Information Technology \\ Peshawar, Pakistan
}

\begin{abstract}
Effective communication play an important role during requirements collection and implementation for any software system. In Global Software Development (GSD), its significance increase more as stakeholders are far away across the globe. In GSD challenges such as language differences and time zone differences exist and thus proper and timely communication become more difficult. There is need of practices for effective communication during proper requirements elicitation and implementation in GSD. This study address validation of possible solutions and practices for effective communication from our previous study.
\end{abstract}

\section{Keywords}

Practices, Effective communication, Practices, Global Software Development, Systematic Literature Review.

\section{INTRODUCTION}

Requirement Engineering (RE) deals with all aspects of software requirements from requirements collection to requirements implementation in systematic and discipline way [1][2][3]. RE consist of different phases. In requirement elicitation phase, requirements for software system are collected from clients by applying various elicitation techniques such as background study, interview, questionnaire, apprenticing [4][5][6][7]. In GSD, where clients and vendors are far away and there exist geographical distance thus traditional ways of applying elicitation techniques are not possible [8][9]. There is need of more collaboration and coordination among clients and vendors in GSD [7][10]. In GSD, use of modern tools and technologies bears more significance. Use of these collaborative modern technologies facilitate effective communication and make elicitation process more and more efficient and successful [11][12]. There are two ways of communication in GSD i.e. synchronous ways of communication such as video chats and asynchronous ways of communication such as fax, emails etc. Through these collaborative tools, both vendors and clients can communicate in both ways [13]. In GSD, vendors and clients possess different cultures and thus difficulties during requirements collection increase more. According to [14], we need practices for effective communication during elicitation phase of RE. With efficient practices, challenges in GSD can be reduced by ensuring effective communication. Effective communication is considered to be the most critical success factor in GSD in many studies [15][16][17]. In our previous research work, SLR was conducted in which success factors for GSD during successful requirements implementation were identified from 92 papers, where effective communication was identified as most critical success factor with frequency of $80 \%$ from different studies [18]. In our research work [19], practices for implementing effective communication in GSD were identified through SLR as shown in Table 1. The aim of this research work is to validate practices for implementation of effective communication in GSD through empirical study.

Table 1: Practices for effective communication in global software development

\begin{tabular}{|c|c|c|}
\hline S/No & Practices & $\begin{array}{c}\text { \% of Practices via } \\
\text { SLR (N=30) }\end{array}$ \\
\hline 1 & $\begin{array}{c}\text { Use asynchronous way of communication like email or watsapp for communicating the } \\
\text { requirements }\end{array}$ & 14 \\
\hline 2 & Use synchronous way of communication like video chats & 5 \\
\hline 3 & Regular and open communication & 9 \\
\hline 4 & The use of collaboration software and tools & 5 \\
\hline 5 & Informal communication is needed & 4 \\
\hline 6 & Face-to-face relationship building & \\
\hline
\end{tabular}




\begin{tabular}{|c|c|c|}
\hline 7 & Using ontologies as bridges to facilitate communication & 4 \\
\hline 8 & Structure of an organization & 1 \\
\hline 9 & Facilitate communication sessions & 1 \\
\hline 10 & Documentation as way of communication & 1 \\
\hline 11 & Train team members & 1 \\
\hline 12 & Social Network Analysis & 1 \\
\hline 13 & Creating a communication coordinator role & 1 \\
\hline
\end{tabular}

\section{RELATED STUDY}

According to [20], due to barriers such as geographical distance, time zone differences and language differences, effective requirements collection and implementation in GSD become more and more difficult which can affect the quality of software systems. Systematic literature review is conducted by [18], where effective communication is identified as most critical success factor during successful requirements implementation in GSD. With effective communication channels, proper elicitation of requirements in GSD can be assured.

Language is very essential in requirement collection as it disturbs transfer of knowledge and proper communication that depends entirely on appropriate usage of language [21]. In GSD this factor is a big challenge because mostly the clients and vendors face difficulties to fully cope the terminologies of other languages. In GSD, timely communication is another big challenge because there exist difference of time zones between two countries and sometimes this variation in time zones can increases that makes it difficult to communicate synchronously such as video or audio calls etc. Time zone variance is a challenge for both vendors and clients in GSD and thus it requires appropriate solutions and practices [22][23].

Elicitation problems occur due to lack of proper communication and for which model is suggested in one of the studies [24]. The first step in this model is to arranged interviews from several software industries and compare the consequences with outcomes as identified by research group. Theoretical modeling of requirements uncertainty and elicitation dimensions is the next step and the last step is the validation of model from different software organizations.

Communicating knowledge and information's in GSD is challenging and a big challenge in GSD [25]. Poor SRS shows that the knowledge managing was improper.

Proper discussion and negotiation on requirements in GSD is an crucial challenge to be overcome and but due to the stated challenges such as time differences, language barriers and culture differences it is quite difficult to have proper negotiations on requirements [26][27]. Trust should be established in GSD because without trust no team is possible and without team no collaboration is possible and without collaboration and trust a success is achieved only by luck [27].
Different implementation models has been for efficient requirements implementation in the context of GSD. Requirement Implementation Model (RIM)[16], Requirement Elicitation Model (REM) [15] and Requirement Management Model (RMM)[11] are presented in different studies. The proposed models are based on empirical studies that will consist of all possible challenges and success factors with practices and solutions during requirements implementation, elicitation and management in context of GSD.

\section{RESEARCH METHOD}

\subsection{Survey Design}

Survey is empirical study that is conducted to validate our outcomes from results of SLR that was formerly conducted [18]. When maximum responses in short time are to be collected, questionnaire survey is best choice. In this research work, online survey is led with software engineering experts. Structured questionnaire method is adopted for gathering data from the experts working in GSD projects.

The questionnaire consists of success factors that were identified through SLR. Five point scale was used to state the importance of the identified intercultural challenges. The respondents were requested to choose one of the seven options i.e. strongly agree, agree, slightly agree, not sure, disagree.

\subsection{Data Sources}

Only those software organization were selected that work on GSD projects. Different organizations were finalized for this purpose and questionnaire were distributed amongst them.

\subsection{Data Analysis}

A total of 35 participants responded to the survey belong to different software houses as shown in Table 2. Among them 5 responses were rejected because of our quality criteria. The experts are selected on the basis of their experience. Final list of responses contain 30 experts. Percentages of strongly agreed, agreed, slightly agreed, not sure and disagreed responses will be calculated for every success factor. This calculation is necessary to analyze these factors and to identify factors that are more critical. Critical factors are those that bears more importance as compare to rest of the factors. Finalized questions in questionnaire form are given in Table 3. 
Table 2: List of software houses selected for questionnaire

\begin{tabular}{|c|c|c|}
\hline S/No & Software Company Name & Address \\
\hline 1 & Datumsquare IT Service & $\begin{array}{l}\text { STP -3, Block A, Ground Floor, Plot \# 155, } \\
\text { Service Road North, Sector I-9/3, Islamabad }\end{array}$ \\
\hline 2 & $\begin{array}{l}\text { Seven Software Development } \\
\text { (Private) Limited }\end{array}$ & $\begin{array}{l}\text { 3rd floor, software technology park, Service } \\
\text { Road North, Sector I-9/3, Islamabad }\end{array}$ \\
\hline 3 & Developer Desk Technologies & House No 258, Street 90, I-8/4, Islamabad \\
\hline 4 & DiscreteLogix & $\begin{array}{c}\text { Software technology park, Service Road North, } \\
\text { Sector I-9/3, Islamabad }\end{array}$ \\
\hline 5 & Techaccess Private Limited & F-8/2, Islamabad \\
\hline 6 & StepNex Services (Pvt) ltd & Deans Trade Center, FF-51, Peshawar \\
\hline 7 & Trend micro logics & Deans Trade Center, FF, Peshawar \\
\hline 8 & Grey Beard Solutions & F-6, Islamabad \\
\hline 9 & Vizteck Solutions & $\begin{array}{c}\text { Software Technology Park, Plot 156, Sector I- } \\
\text { 9/3, Islamabad }\end{array}$ \\
\hline 10 & xFlow Research & $\begin{array}{c}\text { Software Technology Park, } \\
\text { Sector I-9/3,Islamabad }\end{array}$ \\
\hline
\end{tabular}

Table 3: Form for questionnaire

\begin{tabular}{|c|c|c|c|c|c|}
\hline Questions & 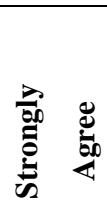 & 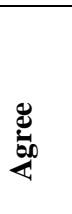 & 䃕 & 离 & 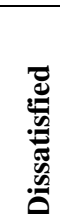 \\
\hline $\begin{array}{l}\text { Use asynchronous way of communication like } \\
\text { email or watsapp for communicating the } \\
\text { requirements }\end{array}$ & $\square$ & $\square$ & $\square$ & $\square$ & \\
\hline $\begin{array}{c}\text { Use synchronous way of communication like } \\
\text { video chats }\end{array}$ & & & $\square$ & & \\
\hline Regular and open communication & $\square$ & [ & $\square$ & & \\
\hline Use of collaboration software and tools & $\square$ & [ & $\square$ & 7 & \\
\hline Informal communication is needed & $\square$ & {[} & $\square$ & 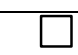 & \\
\hline $\begin{array}{l}\text { Using ontologies as bridges to facilitate } \\
\text { communication }\end{array}$ & $\mathrm{\square}$ & $\square$ & L & $\square$ & \\
\hline structure of an organization & $\square$ & $\square$ & $\square$ & $\square$ & $\square$ \\
\hline Facilitate communication sessions & $\square$ & $\square$ & $\square$ & $\square$ & $\square$ \\
\hline Documentation as way of communication & $\square$ & $\square$ & $\square$ & $\square$ & $\square$ \\
\hline Train team members & $\square$ & $\square$ & $\square$ & $\square$ & $\square$ \\
\hline Social Network Analysis & $\square$ & $\square$ & $\square$ & $\square$ & $\square$ \\
\hline
\end{tabular}

\section{RESULTS}

Results after conducting questionnaire survey are given in Table 4 below. It shows that factors 'Use asynchronous way of communication like email or watsapp for communicating the requirements' is most strongly agreed by industry. Factors that frequency of strongly agreed is greater than $50 \%$ is more critical which shows that implementation of these factors will 
reduce challenges during proper requirements collection in GSD. Other factors whose frequency is low are also important. Figure 1 shows percentages of all practices that are strongly agreed by experts. From the survey it was found that practice 'Use asynchronous way of communication like email or watsapp for communicating the requirements' is most critical with $80 \%$ experts strongly agreed while few are only agreed and none of expert is disagreed. Practices, 'Use synchronous way of communication like video chats' and 'social network analysis' are identified from the results of survey with $66 \%$ experts strongly agreed. With social network analysis, several people can informally combined and share their opinions about successful implementation of requirements. 'Train team members' is identified from survey as important practices with $56 \%$ strongly agreed experts. Training prior to start of the project and during project implementation is necessary. Giving skills to all team members on how to collect and implement software requirements successfully.

Table 4: Practices validation for effective communication in GSD

\begin{tabular}{|c|c|c|c|c|c|}
\hline \multicolumn{2}{|c|}{ Effective Communication Practices } & \multicolumn{2}{|c|}{} & Disagree \\
\cline { 2 - 6 } & $\begin{array}{c}\text { Strongly } \\
\text { agree }\end{array}$ & Agree & $\begin{array}{c}\text { slightly } \\
\text { agree }\end{array}$ & Not sure & 0 \\
\hline $\begin{array}{c}\text { Use asynchronous way of communication like email or } \\
\text { watsapp for communicating the requirements }\end{array}$ & 24 & 8 & 0 & 0 & 0 \\
\hline Use synchronous way of communication like video chats & 21 & 9 & 0 & 0 & 0 \\
\hline Regular and open communication & 2 & 15 & 10 & 3 & 0 \\
\hline Use of collaboration software and tools & 5 & 8 & 7 & 5 & 15 \\
\hline Informal communication is needed & 2 & 3 & 10 & 0 & 7 \\
\hline Using ontologies as bridges to facilitate communication & 0 & 2 & 5 & 16 & 3 \\
\hline structure of an organization & 5 & 12 & 10 & 0 & 0 \\
\hline Facilitate communication sessions & 9 & 20 & 1 & 0 & 0 \\
\hline Documentation as way of communication & 3 & 10 & 10 & 7 & 0 \\
\hline Train team members & 17 & 10 & 3 & 0 & 0 \\
\hline Social Network Analysis & 20 & 10 & 0 & 0 & 0 \\
\hline Creating a communication coordinator role & 4 & 13 & 8 & 4 & 1 \\
\hline
\end{tabular}

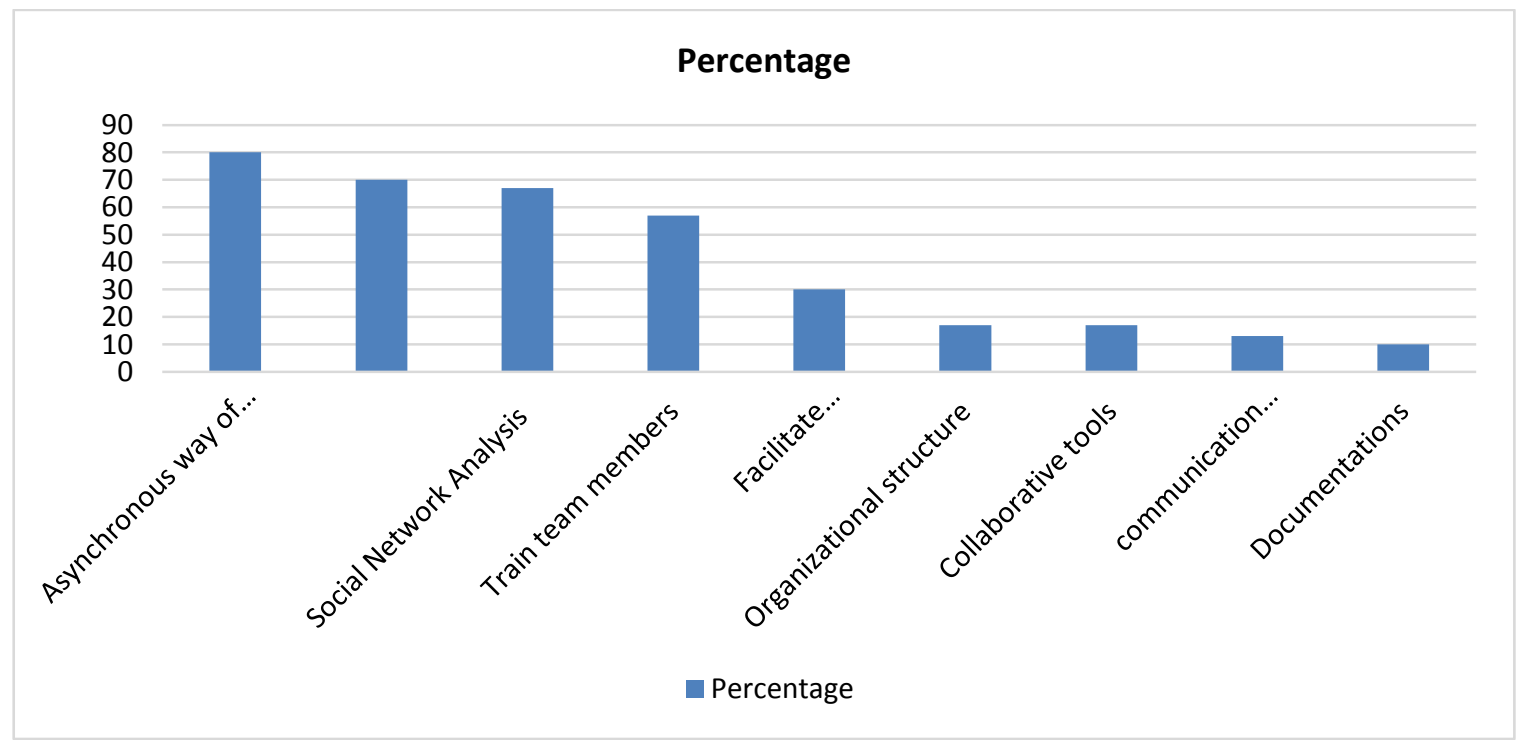

Figure 1: Critical Practices in descending order of percentages of strongly agreed

Figure 2 shows percentages of all practices with positive responses. Positive responses can be either strongly agreed, agreed or slightly agreed while negative response is that either not agreed or not sure. Figure 2 shows that for all practices instead few practices such as informal communications and using ontologies are either not agreed or not sure by experts.
Reason could be that using modern technologies such as software web ontologies is new field and can take time so that people can aware of using it. Practices are that agreed by experts are important but this does not mean that other practices are not important. 


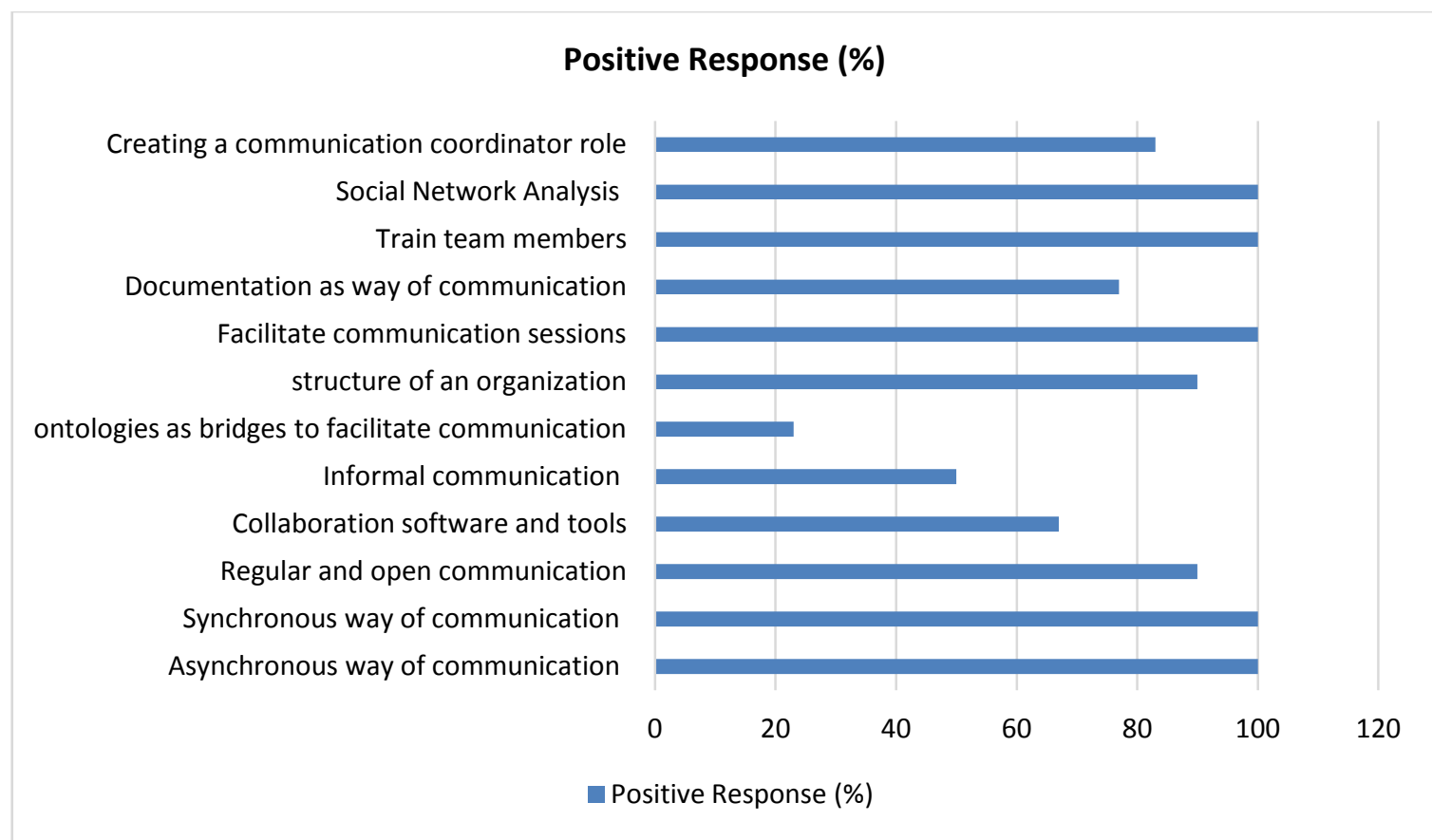

Figure 2: Percentages of positive responses of expert

\section{CONCUSION}

All identified possible best practices from our previous study for implementing effective communication are validated from software industry. From validation it is concluded that all factors are important but some factors such as 'Use asynchronous way of communication like email or watsapp for communicating the requirements', 'Use synchronous way of communication like video chats', 'Train team members', 'Social Network Analysis' are more important and critical. Thus we need to implement these factors so that effective communication can be assured during requirements implementation in GSD.

\section{REFERENCES}

[1] M. Yaseen, A. Mustapha, N. Ibrahim, and U. Farooq, 'International Journal of Advanced Trends in Computer Science and Engineering Effective Requirement Elicitation Process using Developed Open Source Software Systems', vol. 9, no. 1, 2020.

[2] M. Yaseen, A. Mustapha, and N. Ibrahim, 'MINIMIZING INTER-DEPENDENCY ISSUES OF REQUIREMENTS IN PARALLEL DEVELOPING SOFTWARE PROJECTS WITH AHP', vol. 8, no. Viii, 2019.

[3] M. Yaseen, A. Mustapha, and N. Ibrahim, 'Prioritization of Software Functional Requirements: Spanning Tree based Approach', vol. 10, no. 7, pp. 489-497, 2019.

[4] M. Yaseen, A. Mustapha, and N. Ibrahim, 'An Approach for Managing Large-Sized Software Requirements During Prioritization', 2018 IEEE Conf. Open Syst., pp. 98-103, 2019.

[5] M. Yaseen, N. Ibrahim, and A. Mustapha, 'Requirements Prioritization and using Iteration Model for Successful Implementation of Requirements', Int. J. Adv. Comput. Sci. Appl., vol. 10, no. 1, pp. 121-127, 2019.

[6] M. Yaseen, I. Journal, M. Yaseen, A. Mustapha, M. A. Salamat, and N. Ibrahim, 'International Journal of
Advanced Trends in Computer Science and Engineering Available Online

http://www.warse.org/IJATCSE/static/pdf/file/ijatcse099 12020.pdf Prioritization of Software Functional Requirements: A Novel Approach using AHP and Spanning Tree', vol. 9, no. 1, 2020.

[7] M. Yaseen, N. Sarwar, M. Ali, and A. U. R. Rahman, 'Colloboration as Success Factor during Requirement Elicitation in Global Software Development', vol. 6, no. 3, pp. 39-46, 2020.

[8] M. Yaseen and M. A. Awan, 'Practices for Effective Software Project Management in Global Software Development: A Systematic Literature Review', vol. 177, no. 36, pp. 1-6, 2020.

[9] M. Yaseen, A. U. Rahman, I. U. Rahman, Z. Ullah, and M. Bacha, 'Inter-organizational Learning and Knowledge Sharing Management in Global Software Development', vol. 8, no. 1, pp. 52-57, 2020.

[10] M. Yaseen, 'Effective Negotiations Practices in Global Software Development: A Systematic Literature Review', vol. 9, no. 1, pp. 87-91, 2020.

[11] M. Yaseen, Z. Ali, and M. Humayoun, 'Requirements Management Model (RMM): A Proposed Model for Successful Delivery of Software Projects', Int. J. Comput. Appl., vol. 178, no. 17, pp. 32-36, 2019.

[12] Z. Ali and M. Yaseen, 'Critical Challenges for Requirement Implementation in Global Software Development: A Systematic Literature Review Protocol with Preliminary Results', vol. 182, no. 48, pp. 17-23, 2019.

[13] A. U. Rahman, M. Yaseen, and Z. Ali, 'Identification of Practices for Proper Implementation of Requirements in Global Software Development: A Systematic Literature Review Protocol', vol. 177, no. 13, pp. 53-58, 2019.

[14] Z. Ali, M. Yaseen, and S. Ahmed, 'Effective communication as critical success factor during 
requirement elicitation in global software development', vol. 8, no. 03, pp. 108-115, 2019.

[15] M. Yaseen and U. Farooq, 'Requirement Elicitation Model (REM) in the Context of Global Software Development', Glob. J. Comput. Sci. Technol., vol. 1, no. 2, pp. 1-6, 2018.

[16] M. Yaseen, S. Baseer, S. Ali, S. U. Khan, and Abdullah, 'Requirement implementation model (RIM) in the context of global software development', 2015 Int. Conf. Inf. Commun. Technol. ICICT 2015, 2016.

[17] M. Yaseen, R. Naseem, Z. Ali, and G. Ullah, 'IDENTIFICATION OF CHALLENGES DURING REQUIREMENTS IMPLEMENTATION IN GLOBAL SOFTWARE DEVELOPMENT: A SYSTEMATIC', vol. 4, no. 1, pp. 23-40, 2019.

[18] M. Yaseen and Z. Ali, 'Success Factors during Requirements Implementation in Global Software Development: A Systematic Literature Review', vol. 8, no. 3, pp. 56-68, 2019.

[19] M. Yaseen and Z. Ali, 'Practices for Effective Communication during Requirements Elicitation in Global Software Development', vol. 8, no. 06, pp. 240245, 2019.

[20] M. Yaseen, S. Baseer, and S. Sherin, 'Critical Challenges for Requirement Implementation in Context of Global Software Development: A Systematic Literature Review', pp. 120-125, 2015.
[21] T. Illes-Seifert, A. Herrmann, M. Geisser, and T. Hildenbrand, 'The Challenges of Distributed Software Engineering and Requirements Engineering: Results of an Online Survey', 1st Int. Glob. Requir. Eng. Work. GREW 2007, pp. 55-65, 2007.

[22] D. Damian, 'An empirical study of requirements engineering in distributed software projects: is distance negotiation more effective ?', vol. 4, no. 04, pp. 149-152, 2001.

[23] I. Kwan, D. Damian, and S. Marczak, 'The effects of distance, experience, and communication structure on requirements awareness in two distributed industrial software projects', Glob. Requir. Eng. Work. conj. Intl Conf Glob. Softw. Eng. 2007., no. May, 2007.

[24] W. Hussain, J. Buchan, and T. Clear, 'Managing Requirements in Globally Distributed COTS Customization', Proc. - Int. Comput. Softw. Appl. Conf., vol. 18-21-Augu, pp. 33-38, 2014.

[25] D. E. Damian and D. Zowghi, 'RE challenges in multisite software development organisations', no. 2003, pp. 149-160, 2007.

[26] R. Lai and N. Ali, 'A Requirements Management Method for Global Software Development', Humanpub.Org, vol. 1, no. March, pp. 38-58, 2013.

[27] A. M. Søderberg, S. Krishna, and P. Bjørn, 'Global software development: Commitment, trust and cultura sensitivity in strategic partnerships', J. Int. Manag., vol. 19, no. 4, pp. 347-361, 2013. 